\title{
Trichloroethylene exposure Simulation of uptake, excretion, and metabolism using a mathematical model
}

\author{
J. G. FERNÁNDEZ, P. O. DROZ, B. E. HUMBERT, AND J. R. CAPEROS
}

From the Occupational Health and Industrial Hygiene Service, Chemistry Department of the University of Neuchâtel, Bellevaux 51, 2000 Neuchâtel, Switzerland

\begin{abstract}
The absorption, distribution, and excretion of trichloroethylene, as well as the kinetics of formation and elimination of trichloroethanol(TCE) and trichloroaceticacid(TCA) were simulated by a mathematical model. The results of this model have been satisfactorily compared with those obtained experimentally from pulmonary elimination of the solvent and from urinary excretion of the metabolites. The model permitted a study of the distribution of the solvent in the different tissues of the organism as well as an evaluation of the body burden of TCE and TCA. The influence of the duration and repetition of the exposure on the urinary eliminations of TCE and TCA was studied, and showed that the excretion of the first metabolite represents the most recent exposure while that of the second is related to the average exposure of the preceding days. The study of the pulmonary elimination of trichloroethylene during single or repeated exposures showed a linear relationship between the alveolar concentration of the solvent approximately 15 hours after the end of the exposure and the quantity of trichloroethylene accumulated in the fatty tissues.
\end{abstract}

The uptake and elimination of trichloroethylene (TRI), as well as its toxicity for the workers who handle it, have long been topics for research. It is known that during industrial exposure, the solvent is principally absorbed by the lungs. Part of the TRI is retained unchanged in the different body tissues due to its great liposolubility, and some is metabolised and eliminated mainly in urine. Apart from chloral hydrate $(\mathrm{CH})$, trichloroacetic acid (TCA), monochloroacetic acid (MCA), and free or conjugated trichloroethanol (TCE) it is not known exactly which other metabolites can be formed (Müller et al., 1974).

In other publications, we have studied the uptake, excretion, and metabolism of TRI (Fernández et al., 1975) with a view to setting up biological methods for the control of occupational exposure; we have also studied the pulmonary elimination of the solvent (Fernández et al., 1977a) and the urinary excretion of its metabolites (Fernández et al., 1977b). However, despite all our work and that of other authors (Souček and Vlachova, 1960; Bartoníček, 1962; Ogata et al., 1971; Ertle et al., 1972; Müller

Received for publication 9 January 1976. Accepted for publication 26 August 1976. et al., 1972, 1975; Kimmerle and Eben, 1973; Stewart et al., 1974), it is still difficult to understand and define with any certainty the relationships that exist between the degree of exposure and the excretion of the solvent and its metabolites.

We thought therefore it would be interesting to study the processes of the absorption, distribution and elimination of TRI, as well as the kinetics of the formation and excretion of its metabolites, using a mathematical model. For the purpose of this study it is assumed that the distribution of TRI in the body takes place in three groups of tissues (the very vascular tissues, the muscles and skin, and the adipose tissues), whereas the kinetics depend mainly on the volumes, partition coefficients, and blood perfusions of the different groups. In addition, it is considered that TRI is quantitatively transformed in the liver to chloral hydrate, precursor of TCA and TCE, and the evolution of these metabolites is studied using the corresponding rate constants for the biotransformations and transfers which occur.

After a comparison of the theoretical values with experimental data for the pulmonary elimination of TRI and the urinary excretion of its metabolites, the mathematical model will be used to study, 
either for repeated or isolated exposures, certain parameters which are inaccessible experimentally, such as the distribution of TRI in the body and the quantities of TCE and TCA retained in the organism.

\section{Theoretical bases}

The uptake, distribution, and elimination of TRI are simulated using a mathematical model similar to that previously developed for our study of the distribution of tetrachloroethylene in the body (Guberan and Fernández, 1974). In the current study, however, cardiac output and alveolar ventilation are considered as being continuous processes. The principal hypotheses used are the same as those discussed in detail by Kety (1951), Eger (1963), and Mapleson (1963):

The solvent diffuses freely through the entire surface of the capillary and alveolar walls.

The concentration of the solvent in venous blood is in equilibrium with that dissolved in the corresponding tissue.

The concentration of the solvent in arterial blood is in equilibrium with that in the alveolar air.

For all tissues, the gas tissue partition coefficient which determines the equilibrium between blood and tissue, is independent of the solvent concentration.

The alveolar ventilation and cardiac output are considered as being continuous instead of cyclic processes.

The circulation time from the lungs to the tissues is not significant.

The metabolism of TRI takes place mainly in the liver, in the presence of NADPH and oxygen (Leibman, 1965). The first known metabolite resulting from this biotransformation is chloral hydrate (Butler, 1949; Byington and Leibman, 1965). In order to develop a unified approach to the metabolic fate of TRI, it is essential to define quantitatively this former reaction. It will, therefore, be assumed that the biotransformation of TRI takes place solely in the liver and that this process is an instantaneous one, so that the biotransformation of TRI is limited by the blood flow through the liver. In addition, it will be considered that the liver is perfused by blood which has an arterial concentration of TRI. The only repercussions of this simplification are in the first few minutes of uptake or elimination, as the vessel-rich tissues which make up the hepatoportal system are nearly always in equilibrium with the arterial blood.

It is important to have an understanding of the metabolic fate of TRI if a simulation of the formation and elimination of TCE and TCA is to be made. Chloral hydrate, formed in the liver, is metabolised mainly by oxidation to TCA and by reduction to TCE. These metabolites are then eliminated in urine, and in less significant quantities by other excretion routes, such as the bile (Bartoniček, 1962). Furthermore, it has been established that TCA is itself a metabolite of TCE (Marshall and Owens, 1954; Müller et al., 1974) that is, there is a direct biotransformation from TCE to TCA. Finally, it is well known that before being eliminated in urine, TCE is transformed by conjugation to glucuronide (TCE-G). These reactions are shown in Fig. 1, in which a rate constant is allotted to each. It should also be noted that for the purposes of this study besides being excreted by routes other than in urine, both TCE and TCA are eliminated by other biotransformations which are still unknown. In fact, various studies have shown that the total amount of the two metabolites eliminated in urine represents only about half of the quantity of chloral hydrate (Müller et al., 1974) or TRI absorbed (Fernández et al., 1975). Although this difference could result partly from an unknown biotransformation of chloral hydrate, all other possible metabolic processes are considered as arbitrarily issuing from TCE and TCA. Nevertheless, this simplification does not change the overall pattern of the system.

As the various stages of the metabolism are not known, at least quantitatively, a number of hypotheses must be defined:

All the rate constants of the reactions shown in Fig. 1 are considered as being first order reactions for the concentrations occurring during industrial exposure.

As the half-life of chloral hydrate in the body is low (Kimmerle and Eben, 1973; Breimer et al., 1974) compared with that of TCA and TCE, the biotransformation of chloral hydrate to its various metabolites can be considered as being instantaneous. Only the ratios of these constants are therefore important.

The distribution of TCA and TCE in the body takes place for each product in one single volume, $\mathrm{V}_{\text {TCA }}$ and $\mathrm{V}_{\text {TCE }}$, respectively. This hypothesis can be considered as being realistic only if the equilibrium rate of these two metabolites in the various tissues is significantly greater than that of their formation.

As the kinetics of free TCE and TCE glucuronide are similar (Breimer et al., 1974), no distinction will be made between the two in the mathematical model. Only the sum of the two will be taken into consideration.

All the hypotheses mentioned previously concerning the distribution of TRI and the elimination of its metabolites allow the elaboration of a mathematical model, leading to a complete description of 


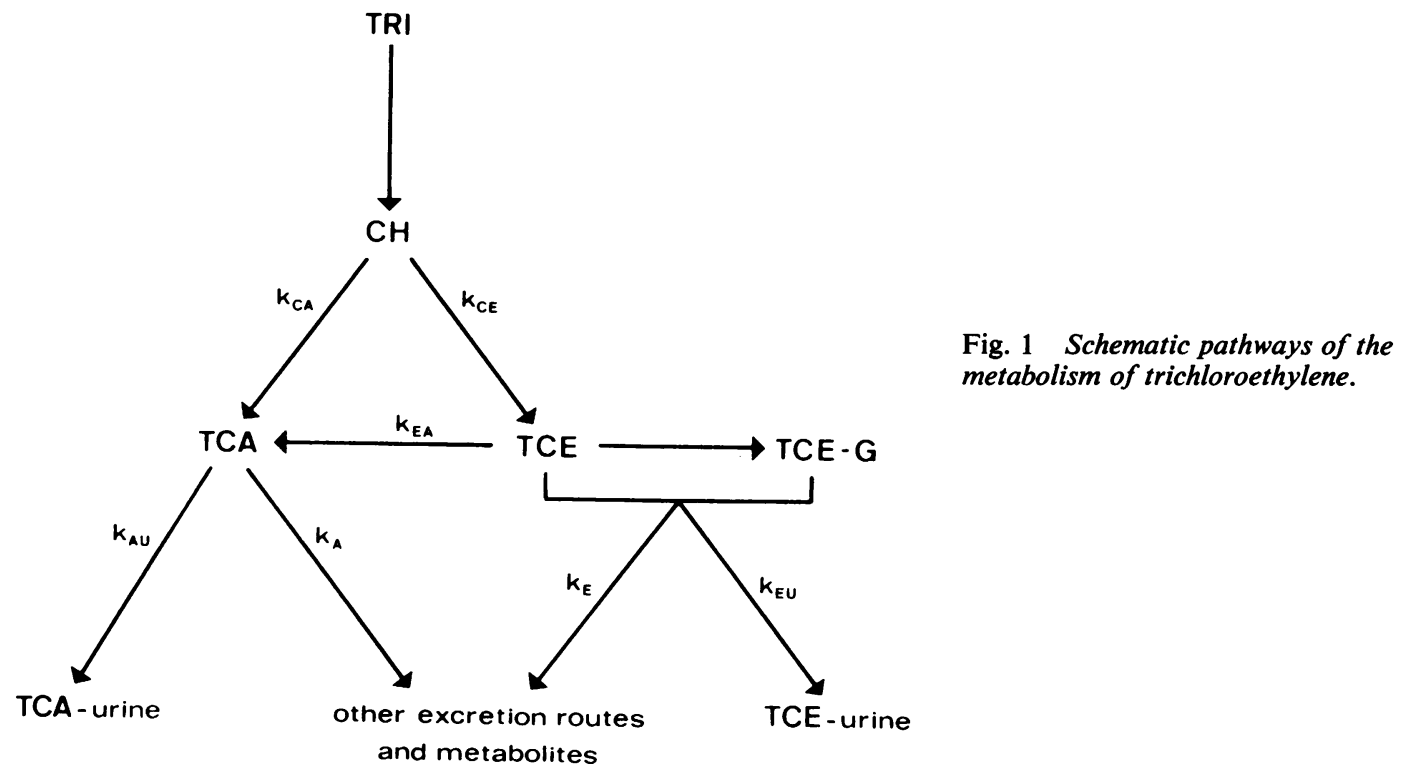

the processes resulting from an isolated or repeated absorption of TRI. The mathematical development of this model is described in detail in the Appendix.

\section{Methods}

UPTAKE, DISTRIBUTION, AND ELIMINATION OF TRICHLOR OETHYLENE

In order to simulate the uptake, distribution, and elimination of TRI, the body is considered to consist of a pulmonary compartment (arterial blood, pulmonary tissue, and alveolar air), an organ responsible for the metabolisation (liver) and of several tissues grouped according to Mapleson (1963): the tissue of the vessel-rich group excluding the liver (VRG), the low perfused tissue such as muscle and skin (MG), and the poorly perfused fatty tissue (FG).

For a standard man (body weight $70 \mathrm{~kg}$, body surface area $1.8 \mathrm{~m}^{2}$ ), the volume and perfusion of these different tissues, as well as the volume of blood in equilibrium with them (venous blood distributed in proportion to the blood perfusion of the tissue) are shown in Table 1 (Cowles et al., 1971). The volume of alveolar air is determined by the functional residual capacity $(2.43 \mathrm{l})$ plus half the tidal volume $(250 \mathrm{ml})$ (Cowles et al., 1971). Table 1 also shows the partition coefficients for the equilibrium between air and blood, liver, adipose tissues (Steward et al., 1973), and muscles (Hagler, 1969). The partition between air and the vessel-rich group has been estimated separately from the proposed values for the brain, the kidneys, and the liver (Steward et al., 1973). The lung tissue-gas partition coefficient is assumed to be the same as the blood-gas partition coefficient.

For the cardiac output $(6.51 / \mathrm{min})$, the cardiac index of $3.51 / \mathrm{min}$ per $\mathrm{m}^{2}$ (Cowles et al., 1971) is combined with the $1.87 \mathrm{~m}^{2}$ estimated surface area (Documenta Geigy, 1963) of our 20 experimental subjects $(71 \mathrm{~kg}, 177 \mathrm{~cm}$ ) (Fernández et al., 1977b). The right-to-left shunt at the lungs is assumed to be $2 \%$ of the cardiac output. The alveolar ventilation used corresponds to a value at rest of $5.51 / \mathrm{min}$

Table 1 Tissue volumes, blood perfusions, blood volumes, and partition coefficients

\begin{tabular}{|c|c|c|c|c|c|}
\hline & $V R G$ & $M G$ & $F G$ & Liver & $\begin{array}{l}\text { Pulmonary } \\
\text { compartment }\end{array}$ \\
\hline $\begin{array}{l}\text { Tissue volume }(1)^{*} \\
\text { Blood volume }(1)^{*} \\
\text { Blood perfusion }(\%)^{*} \\
\text { Partition coefficient } \dagger \neq\end{array}$ & $\begin{array}{l}7 \cdot 1 \\
2 \cdot 59 \\
55 \cdot 1 \\
20\end{array}$ & $\begin{array}{l}36 \cdot 3 \\
0 \cdot 63 \\
15 \cdot 7 \\
19\end{array}$ & $\begin{array}{l}11 \cdot 5 \\
0 \cdot 18 \\
4 \cdot 5 \\
600\end{array}$ & $\begin{array}{l}1 \cdot 7 \\
0 \cdot 60 \\
24 \cdot 7 \\
20\end{array}$ & $\begin{array}{l}1 \cdot 0 \\
1 \cdot 4 \\
\frac{9}{-}\end{array}$ \\
\hline
\end{tabular}

*Cowles, et al. (1971)

†Steward, et al. (1973)

†Hagler (1969) 
(BTPS) and is of the same order of magnitude as the one estimated for the exposed subjects, thus allowing a comparison to be made between experimental and theoretical results.

THE KINETICS OF FORMATION AND

ELIMINATION OF TCE AND TCA

According to our hypotheses concerning the reactions shown in Fig. 1, the following parameters must be determined in order to simulate the kinetics of the formation and elimination of trichloroethylene metabolites (TCE and TCA):

$\mathrm{k}_{\mathrm{EU}}=$ urinary elimination rate constant of TCE.

$\mathbf{k}_{\mathrm{AU}}=$ urinary elimination rate constant of TCA.

$\mathrm{k}_{\mathrm{E}}=$ elimination rate constants of TCE by other excretion routes or metabolic pathways.

$\mathrm{k}_{\mathrm{A}}=$ elimination rate constant of TCA by other excretion routes or metabolic pathways.

$\mathrm{kEA}_{\mathrm{EA}}=$ rate constant of the transformation of TCE to TCA.

$\mathrm{k}_{\mathrm{CE}} /\left(\mathrm{k}_{\mathrm{CE}}+\mathrm{k}_{\mathrm{CA}}\right)=$ percentage of $\mathrm{CH}$ transformed in TCE.

$\mathrm{k}_{\mathrm{CA}} /\left(\mathrm{k}_{\mathrm{CE}}+\mathrm{k}_{\mathrm{CA}}\right)=$ percentage of $\mathrm{CH}$ transformed in TCA.

As a mathematical model independent of the experimental results obtained from exposure to trichloroethylene is desired, these constants will be estimated from kinetic and percentage studies determined in vivo after absorption of $\mathrm{CH}$, TCE, and TCA.

The following combinations of constants can be deduced from measuring the decrease of TCE or TCA in blood in humans after absorption of these products (Müller et al., 1974):

$\mathrm{k}_{\mathrm{EU}}+\mathrm{k}_{\mathrm{EA}}+\mathrm{k}_{\mathrm{E}}=0.0533 \mathrm{~h}^{-1}$,

$\mathrm{k}_{\mathrm{AU}}+\mathrm{k}_{\mathrm{A}}=0.0137 \mathrm{~h}^{-1}$

After repeated absorption of chloral hydrate the total percentage of TCA formed may be determined by measuring the daily amount of TCA eliminated in urine (Owens and Marshall, 1955). This percentage can also be estimated by examining the total excretion of TCA after a single exposure to chloral hydrate (Marshall and Owens, 1954; Müller et al., 1974). This value is a combination of several rate constants:

$$
\begin{array}{r}
{\left[\frac{k_{C A}}{k_{C E}+k_{C A}}+\frac{k_{C E}}{k_{C E}+k_{C A}} \cdot \frac{k_{E A}}{k_{E U}+k_{E A}+k_{E}}\right]} \\
\frac{k_{A U}}{k_{A}+k_{A U}}=0.25
\end{array}
$$

The total amount of $\mathrm{CH}$ changed into TCE is determined by extrapolation by means of the elimination rate constant and the quantity of TCE excreted in urine during the 24 hours after injection of chloral hydrate (Marshall and Owens, 1954):

$$
\frac{k_{C E}}{k_{C A}+k_{C E}} \cdot \frac{k_{E U}}{k_{E U}+k_{E}+k_{E A}}=0.38
$$

The percentage found by Müller et al. (1974) is not considered as this appears very small compared with the average values obtained in exposures to trichloroethylene.

The proportion of TCA produced by direct transformation may be determined after absorption of chloral hydrate because it has an extremely short half-life. This is accomplished by measuring the TCA concentration in the plasma approximately half an hour after absorption and by estimating the distribution volume as being about $25 \%$ of the body weight (Paykoç and Powell, 1945; Marshall and Owens, 1954; Müller et al., 1974). Thus, if the quantity of TCA eliminated in urine is considered negligible, the value obtained is equal to this combination:

$$
\frac{\mathrm{k}_{\mathrm{CA}}}{\mathrm{k}_{\mathrm{CE}}+\mathrm{k}_{\mathrm{CA}}}=0.22
$$

By evaluating the total quantity of TCA eliminated in urine after absorption of this product, one can estimate the percentage of urinary excretion of TCA and thus determine the ratio (Müller et al., 1974):

$$
\mathrm{k}_{\mathrm{AU}} / \mathrm{k}_{\mathrm{A}}=1 \cdot 0
$$

The rate constants and the percentages calculated with these values are given in Table 2 .

Table 2 Rate constants of the formation and elimination of $C H, T C E$, and TCA

\begin{tabular}{ll}
\hline Rate constant & Numerical value \\
\hline $\mathbf{k}_{\mathrm{EU}}$ & $0.0260 \mathrm{~h}^{-1}$ \\
$\mathbf{k}_{\mathrm{AU}}$ & $0.00685 \mathrm{~h}^{-1}$ \\
$\mathbf{k}_{\mathbf{E}}$ & $0.00820 \mathrm{~h}^{-1}$ \\
$\mathbf{k}_{\mathrm{A}}$ & $0.00685 \mathrm{~h}^{-1}$ \\
$\mathbf{k}_{\mathrm{EA}}$ & $0.0191 \mathrm{~h}^{-1}$ \\
$\mathbf{k}_{\mathrm{CE}} /\left(\mathrm{k}_{\mathrm{CE}}+\mathrm{k}_{\mathrm{CA}}\right)$ & 0.78 \\
$\mathbf{k}_{\mathrm{CA}} /\left(\mathbf{k}_{\mathrm{CE}}+\mathrm{k}_{\mathrm{CA}}\right)$ & 0.22 \\
\hline
\end{tabular}

\section{Results and discussion}

COMPARISON WITH EXPERIMENTAL DATA In order to test the hypothesis of the model concerning the quantitative biotransformation of TRI in the liver, the theoretical results of the biotransformation of TRI for pulmonary excretion are compared with the alveolar air concentrations obtained experimentally. Figure 2 shows the results of 20 exposures to TRI, each lasting 8 hours at concentrations varying between 54 and 160 ppm (Fernández et al 


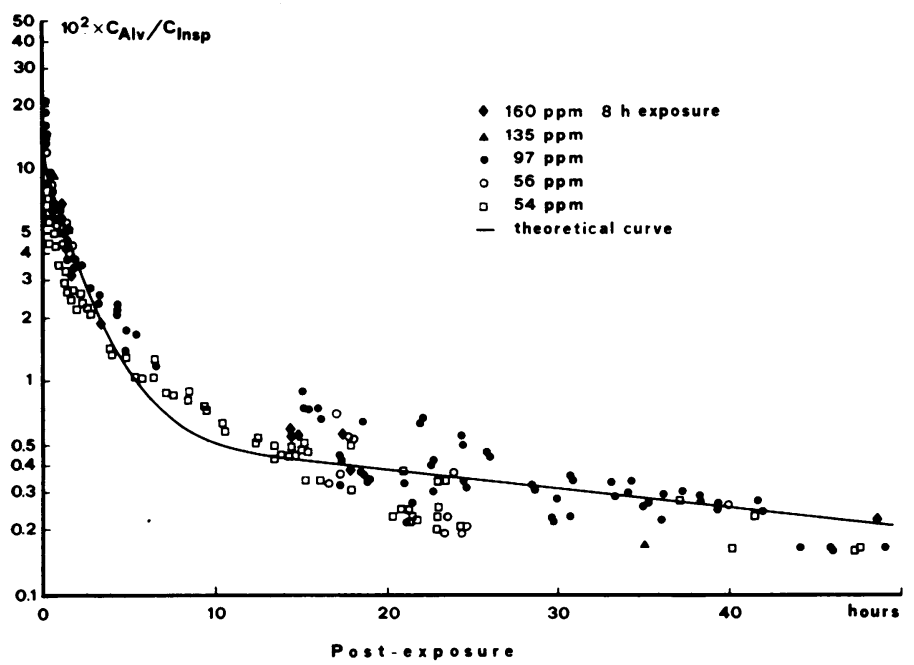

Fig. 2 Alveolar concentrations of trichloroethylene after 8 hours' exposure. Comparison of the theoretical curve and the experimental data.

1977a) and the corresponding elimination curve obtained using the model. As can be seen, there is good agreement between the theoretical and experimental values. The variation which appears between the fifth and twelfth hour after the end of exposure, corresponds approximately with the period during which the exposed subjects slept and most probably results at least partly from a modification of the physiological parameters such as alveolar ventilation and cardiac output.

The simulation of the metabolic processes of TRI depends on the distribution of the solvent in the body and also on the hypotheses concerning the kinetics and transfer of the metabolites. The theoretical values predicted by the model for the elimination of TCE and TCA in urine have therefore been compared with experimental data. Figures 3 and 4 show the evolution of the total quantities of TCE and TCA respectively eliminated during and after exposures lasting 8 hours. The experimental results shown here (Fernández et al., 1977b), obtained during exposures at 54 and $97 \mathrm{ppm}$, are linearly corrected to $100 \mathrm{ppm}$. As before, the results of the model correspond well with those obtained experimentally.

\section{PARTIAL PRESSURES OF TRI IN THE BLOOD} AND TISSUES

The kinetics of the saturation and desaturation of the tissues depend on their blood perfusions and apparent volumes of distribution. Figure 5 shows the evolution of the partial pressures of TRI in the different body tissues during and after an exposure lasting 8 hours. It appears that the group of very vascular tissues which has the greatest blood perfusion and the least volume of distribution, is nearly always in equilibrium with the arterial blood, while the concentration of TRI in the adipose tissues

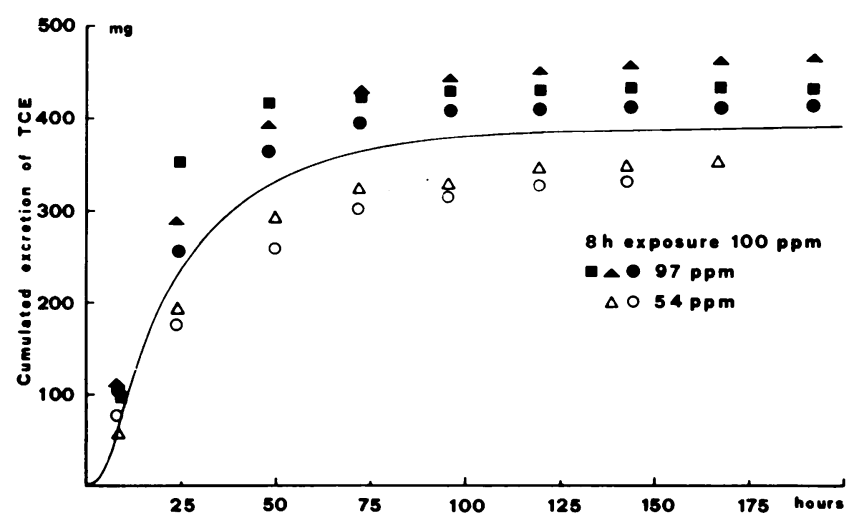

Fig. 3 Total amounts of TCE excreted in urine after 8 hours' exposure to 97 ppm (3 subjects) and 54 ppm (2 subjects). Experimental data are linearly corrected to $100 \mathrm{ppm}$. 


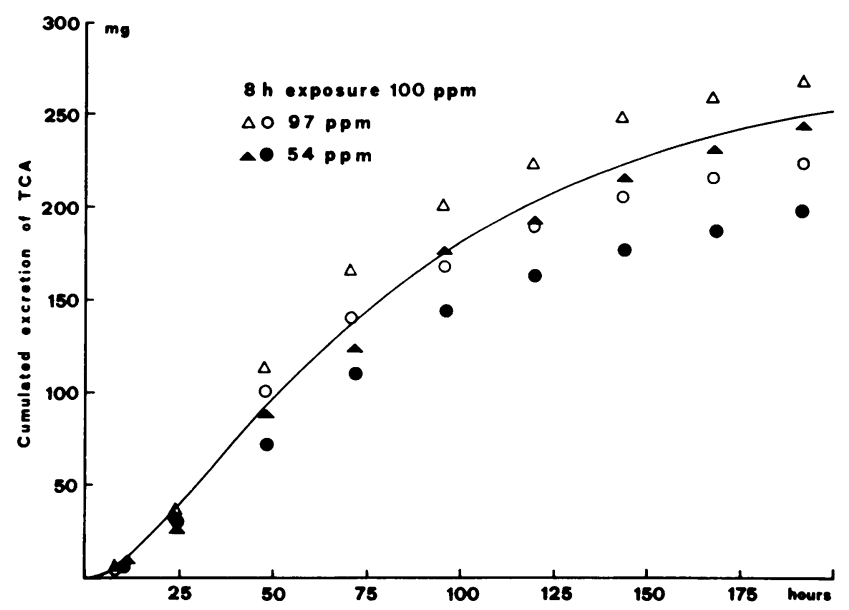

Fig. 4 Total amounts of TCA excreted in urine after 8 hours' exposure to 97 ppm (2 subjects) and 54 ppm (2 subjects). Experimental data are linearly corrected to $100 \mathrm{ppm}$.

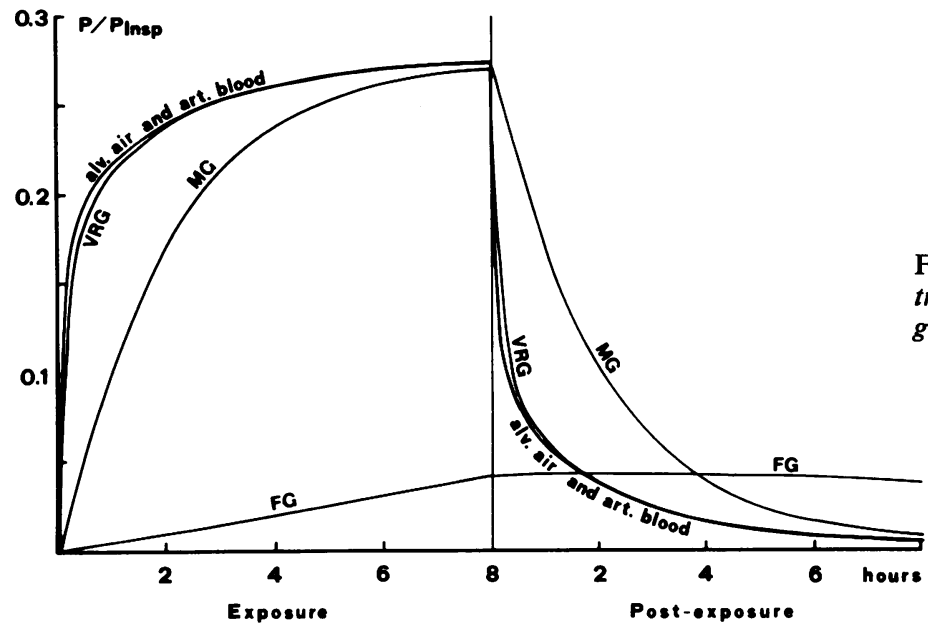

Fig. 5 Predicted partial pressure of trichloroethylene in alveolar air and tissue groups during and after 8 hours' exposure.

(FG) increases only very slowly. This concentration of TRI, as in the case of tetrachloroethylene (Guberan and Fernández, 1974) or benzene (FiserovaBergerova et al., 1974), continues to increase after the end of exposure. The evolution of the partial pressure of TRI in the muscles and skin, the tissue group which has average physiological parameters, is indicated as being intermediate between FG and VRG, but being more like the latter.

In addition, by comparing the results shown in Fig. 5 with those obtained for tetrachloroethylene (Guberan and Fernández, 1974), a substance which is not metabolised in the body but which has approximately the same physicochemical properties as TRI, the influence of the metabolism of the solvent on the partial pressures in the different tissues can be estimated. It is thus observed that these are significantly reduced and rapidly reach a state of equilibrium for the tissues having the greatest blood perfusion. In fact in the case of TRI the partial pressures no longer reach the inspired concentration, but stabilise at a lower level determined by the degree of transformation, the air-blood partition coefficient, the blood perfusion of the tissues where metabolism takes place, and the alveolar ventilation. Consequently the quantity of the solvent absorbed is greater since it directly depends on its concentration in the blood.

URINARY ELIMINATION RATES OF TCE AND TCA

Figures 6 and 7 show the urinary elimination rates of TCE and TCA, during and after four exposures lasting $1,2,4$, and 8 hours at $100 \mathrm{ppm}$. These curves are analogous to those drawn from results obtained during controlled experiments.

It has often been found experimentally that there 


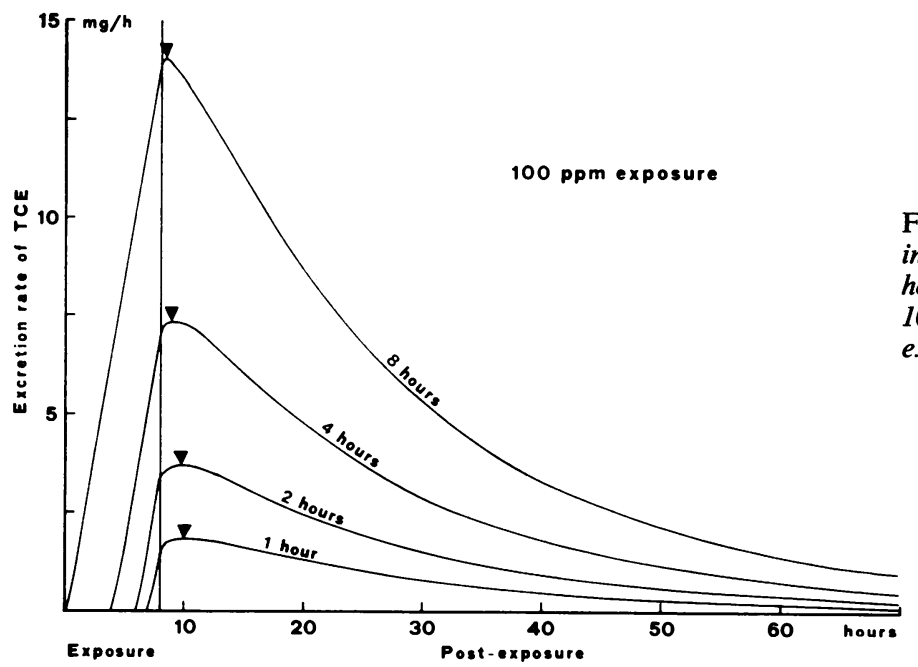

Fig. 6 Predicted excretion rate of TCE in urine during and after 1, 2, 4, and 8 hours of trichloroethylene exposure to $100 \mathrm{ppm} . \mathbf{\nabla}$ indicates the maximum excretion rate.

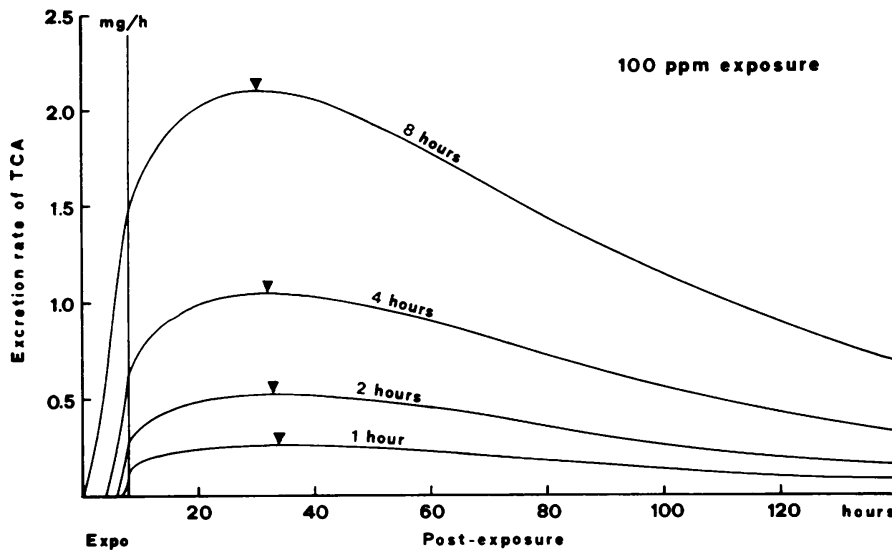

Fig. 7 Predicted excretion rate of $T C A$ in urine during and after $1,2,4$, and 8 hours of trichloroethylene exposure to $100 \mathrm{ppm}$. $\rightarrow$ indicates the maximum excretion rate.

is a significant delay in the excretion of TCA, whereas the maximum excretion rate of TCE is reached immediately after the end of exposure. In addition, positions of the maximum elimination rates of TCA and TCE vary according to the length of exposure.

The urinary elimination rates of TCE and TCA are proportional to the concentration of exposure, due to the principal hypotheses of the model. It should also be noted that these graphs show an approximately linear relationship between the length of exposure and the elimination rates of the two metabolites. Hence, the urinary elimination rate (amount eliminated per unit of time), as well as the urinary concentration of TCE and TCA, linearly reflect the average exposure to TRI. In fact an increase in the concentration of the exposure is approximately equivalent to an increase in the length of exposure.

BODY BURDEN OF TRI, TCE, AND TCA

The mathematical model in this study enables an estimation to be made of the quantities of TRI retained in the different parts of the body. In addition, if the excretion of TCE and TCA by other excretion routes is considered to be about $10 \%$ of the urinary elimination (Bartoniček, 1962), it is possible to estimate the quantities of these two metabolites retained in the body. Figure 8 shows the evolution of the quantities of TRI in the body (VRG, MG, FG, and total), as well as those of TCE and TCA during and after an exposure lasting 8 hours at $100 \mathrm{ppm}$.

It is also observed that by the end of exposure, 


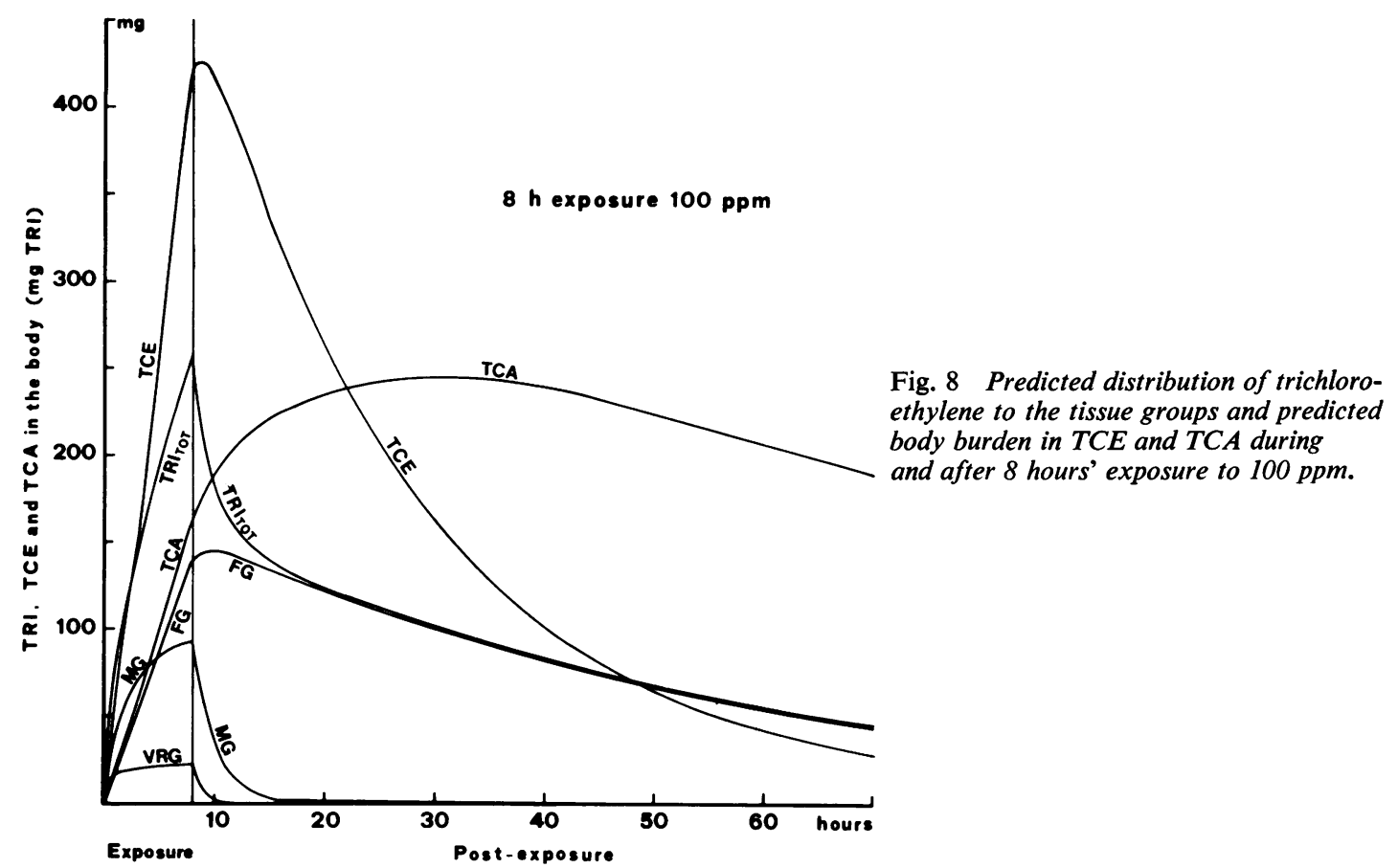

$54 \%$ of TRI absorbed has already been transformed to TCE and $20 \%$ to TCA, while only $26 \%$ remains unchanged $(2 \%$ in the VRG, $9 \%$ in the MG, $15 \%$ in the FG). Just after the end of exposure, the amount of TRI metabolised increases even more and finally reaches the total of $92 \%$. Likewise, the percentage of TCA increases to $27 \%$, partly due to the formation of chloral hydrate from TRI, but particularly due to the biotransformation of TCE. This biotransformation also decreases the total percentage of TCE formed $(41 \%)$.

At the end of exposure, the amounts of TRI in the VRG and MG decrease rapidly, while the quantity of the solvent retained in the FG continues to increase for about one hour. Regarding the metabolites, the TCE body burden continues to rise slightly for half an hour, whereas that of TCA does so progressively for about 30 hours. Therefore, the urinary concentration of TCA increases also.

This delay in the elimination of TCA is due to a combination of two properties of the total system. Firstly, the urinary elimination rate of TCA is very slow owing to its great affinity for proteins (Sellers and Koch-Weser, 1971). Secondly, TCA is formed not only directly from TRI by the intermediary chloral hydrate, but also by the biotransformation of TCE. For this reason, as long as the formation rate of TCA, which is principally determined after the end of exposure by the body burden of TCE, is greater than its excretion rate, the amount of TCA in the body increases as well as its elimination rate. After about 30 hours, these two processes are quantitatively reversed and it is only then that the real depletion of TCA begins. Thus, after repeated exposures, the accumulation of this metabolite in the body would be expected to be considerable.

REPEATED EXPOSURES AND ALVEOLAR AIR

As can be seen in Fig. 8, 24 hours after the start of exposure to TRI the release by the body of the solvent itself and of its two metabolites (TCE and TCA) is still incomplete. In fact, only $56 \%$ of TRI retained at the end of an exposure lasting 8 hours is eliminated during the following 16 hours (curve TRI TOT). Similarly, half of the TCE formed and retained in the organism during this period remains in the body. However, in the case of TCA, the quantity present in the body increases by $42 \%$ during the 16 hours after exposure. It can be expected that notable modifications to the total pattern of the processes arising from the absorption of TRI will occur if the exposure is repeated day after day. So to gain a better understanding of the absorption, distribution, elimination, and metabolic processes of repeated exposures, we used the model to simulate a situation of this type, assuming that the behaviour of the 
organism towards TRI is not significantly modified by repeated absorption of this solvent (Ikeda and Imamura, 1973).

Table 3 shows the alveolar concentrations obtained after repeated exposures at 100 ppm ( 5 days, 6 hours/day). It can be seen that the alveolar concentrations of TRI at the end of exposure vary only slightly from one day to another. As previously stated, the VRG and MG tissues are practically in equilibrium with the arterial blood at the end of exposure (Fig. 5) and the burden of TRI in these tissues increases only slightly daily. On the other hand, as Fig. 9 shows, the partial pressures in the FG for repeated exposure (5 days, 6 hours/day), the quantity of TRI in the adipose tissues progressively increases because of the slow release of the solvent during the elimination period. It is remarkable to find that the adipose tissues have only a minimum effect on the alveolar concentrations during exposure and first hours after exposure. On the other hand, the alveolar concentrations 18 hours after the end of exposure (Table 3 ) show variations which are directly proportional to those observed for the partial pressure of TRI in the FG. Consequently, the measurement of the concentration in alveolar air during the first few hours after exposure essentially reflects the retention of the
VRG and MG, while the same analysis carried out immediately before the following exposure enables an estimation to be made of the quantities of TRI retained in the FG.

REPEATED EXPOSURES AND METABOLITES

The behaviour of TCE and TCA in the body after repeated exposure can be studied by discussing the urinary excretion rate given by the model for these two metabolites, this parameter itself being directly proportional to the quantity present in the body and to the concentration in the blood and urine. Figures 10 and 11 show the elimination rates of TCE and TCA during repeated exposures at $100 \mathrm{ppm}$ ( 5 days, 6 hours/day). It is interesting to note that the form of the curves shown in these two graphs generally follows the variation in concentration of these two metabolites determined experimentally in the blood (Müller et al., 1972). Using the model, the main difference in the behaviour of these after repeated exposures can be seen. While the urinary elimination rate of TCE increases only slightly from day to day and seems to reach a stable rate by approximately the third day (Fig. 10), the excretion of TCA increases steadily throughout the whole week (Fig. 11). Consequently, the excretion rate of TCE in urine is principally determined by the most

Table 3 Predicted alveolar concentrations ( $\mathrm{ppm}$ ) after repeated exposure to $100 \mathrm{ppm}$ (5 days, 6 hours/day)

\begin{tabular}{|c|c|c|c|c|c|}
\hline \multirow[t]{2}{*}{ Day of the week } & \multicolumn{5}{|c|}{ Post-exposure time } \\
\hline & $0 \min$ & $30 \mathrm{~min}$ & $60 \mathrm{~min}$ & $120 \mathrm{~min}$ & $18 h$ \\
\hline $\begin{array}{l}\text { Monday } \\
\text { Tuesday } \\
\text { Wednesday } \\
\text { Thursday } \\
\text { Friday }\end{array}$ & $\begin{array}{l}27 \cdot 0 \\
27 \cdot 3 \\
27 \cdot 5 \\
27 \cdot 6 \\
27 \cdot 7\end{array}$ & $\begin{array}{l}7 \cdot 82 \\
8 \cdot 10 \\
8 \cdot 28 \\
8 \cdot 38 \\
8 \cdot 45\end{array}$ & $\begin{array}{l}5 \cdot 68 \\
5 \cdot 96 \\
6 \cdot 13 \\
6 \cdot 23 \\
6 \cdot 30\end{array}$ & $\begin{array}{l}3 \cdot 48 \\
3 \cdot 76 \\
3 \cdot 92 \\
4 \cdot 03 \\
4 \cdot 09\end{array}$ & $\begin{array}{l}0.32 \\
0.52 \\
0.64 \\
0.71 \\
0.76\end{array}$ \\
\hline
\end{tabular}

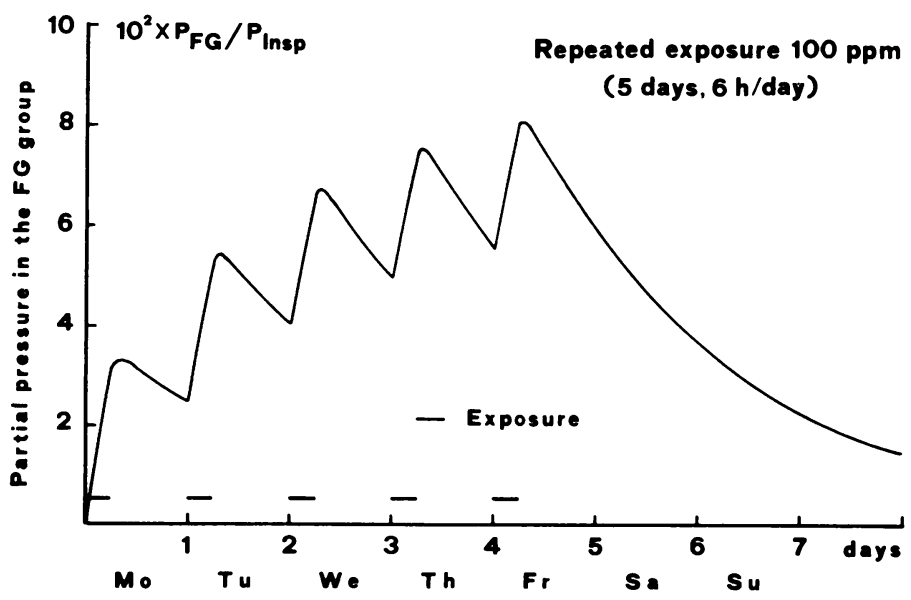

Fig. 9 Predicted partial pressure of trichloroethylene in fatty tissue for a repeated exposure to $100 \mathrm{ppm}$ (5 days, 6 hours/day). 


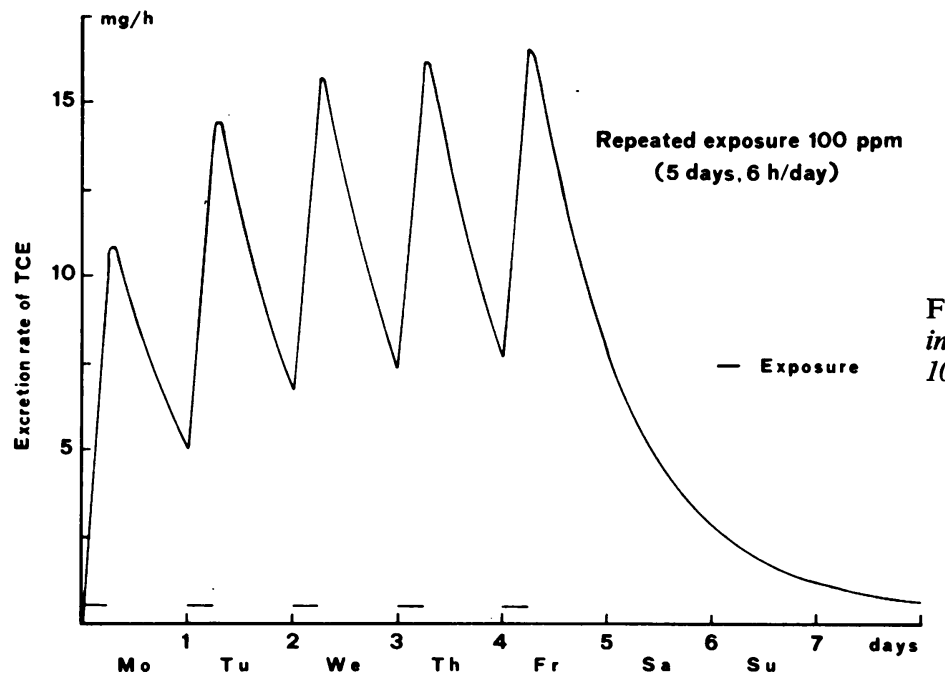

Fig. 10 Predicted excretion rate of TCE in urine for a repeated exposure to 100 ppm (5 days, 6 hours/day).

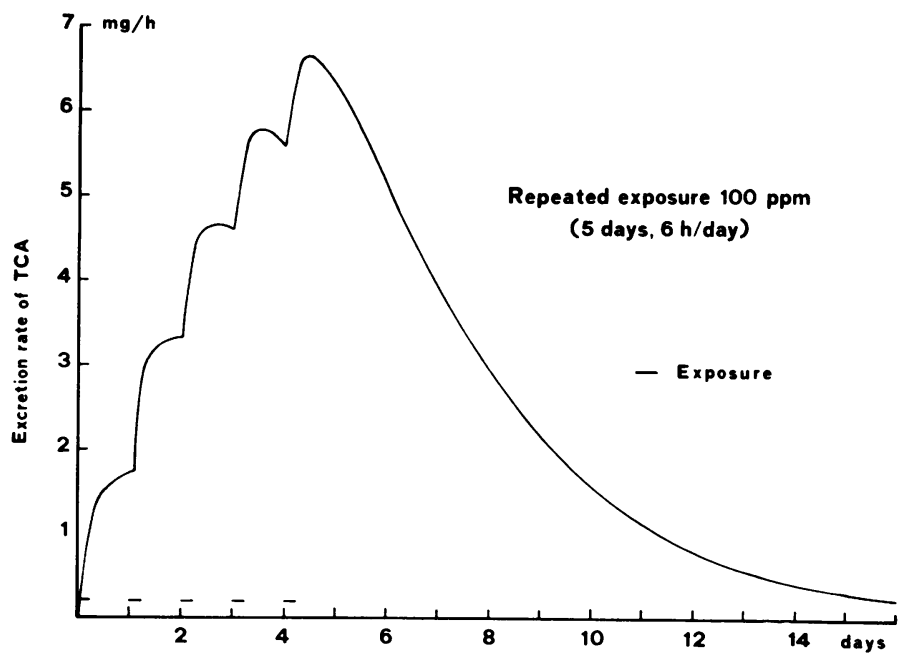

Fig. 11 Predicted excretion rate of TCA in urine for a repeated exposure to 100 ppm (5 days, 6 hours/day).

recent exposure, whereas that of TCA represents the accumulation of all earlier exposures.

In order to compare the behaviour of TCA after isolated or repeated exposure, it is useful to study the maximum excretion rate reached by the metabolite. As is seen in Fig. 8, this occurs about 30 hours after an isolated exposure to TRI lasting 8 hours. For repeated exposure (Fig. 11) the urinary elimination rate continues to increase during the first days, and begins to decrease from the third day before the start of the next exposure, that is, the maximum excretion rate of TCA progressively occurs towards the end of exposure. The reason for this is the systematic accumulation of this metabolite in the body after repeated exposures which induce an increase in its body burden and therefore in its elimination rate. The elimination rate rapidly becomes greater than the quantity of TCA formed by unit of time, depending mostly on the amounts of TCE and TRI in the organism which comparatively increase very little from one exposure to another. Hence, the equivalence between the formation and elimination rate of TCA is reached earlier after repeated exposures. This considerable difference between isolated and repeated exposure found using the model indicates that the results of urinary elimination of TCA obtained from isolated experimental exposures cannot directly be extrapolated 


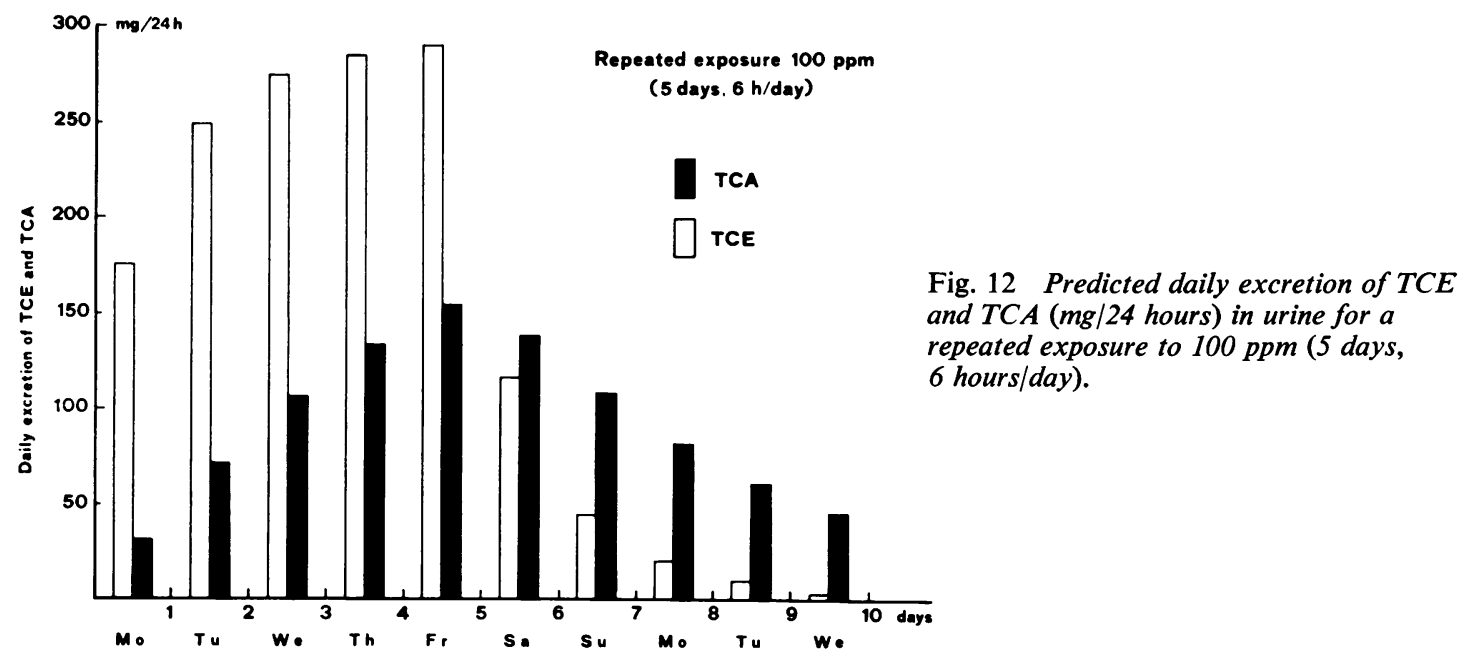

for considering industrial situations, due precisely to the interdependence of these two metabolites.

Figure 12 shows the progression of the daily quantities of the two metabolites excreted in urine after a series of repeated exposures at $100 \mathrm{ppm}$ ( 5 days, 6 hours/day). The theoretical results correspond significantly with the daily eliminations obtained experimentally by other authors (Müller et al., 1972). Once again, it is remarkable that a stable elimination rate of TCE is reached quickly, while in the case of TCA a large increase is maintained throughout the week. As certain authors have already shown experimentally (Nomiyama and Nomiyama, 1971; Müller et al., 1972), the relationship TCE/TCA (mg/24 hours) decreases from day to day and becomes lower than unity as from the sixth day.

\section{Conclusion}

The mathematical model developed in this investigation has allowed a quantitative prediction of absorption, excretion, and metabolism of trichloroethylene. As a result, trichloroethylene post-exposure breath decay curves as well as urinary elimination curves of TCE and TCA can be regarded as methods of monitoring time-weighted average exposures. Nevertheless, it seems that each of these three biological indicators has a different representativity for the estimation of the degree of exposure. Consequently, during an industrial exposure to trichloroethylene, the choice of the biological test depends on the type of exposure and the kind of information desired, while the timing of the collection of samples relative to exposure is determined by the kinetics of elimination of each indicator.
We are grateful to the Fonds National Suisse pour la Recherche Scientifique for financial support. We thank Professor J. Banderet and $\mathrm{Mr}$ Th. Gagnebin of the Institute of Mathematics for their help in computation.

\section{References}

Bartoníček, V. (1962). Metabolism and excretion of trichloroethylene after inhalation by human subjects. British Journal of Industrial Medicine, 19, 134-141.

Breimer, D. D., Ketelaars, H. C. J., and Van Rossum, J. M. (1974). Gas chromatographic determination of chloral hydrate, trichlorethanol and trichloracetic acid in blood and urine employing head-space analysis. Journal of Chromatography, 88, 55-63.

Butler, T. C. (1949). Metabolic transformations of trichlorethylene. Journal of Pharmacology and Experimental Therapeutics, 97, 84-92.

Byington, K. H., and Leibman, K. C. (1965). Metabolism of trichlorethylene in liver microsomes. II. Identification of the reaction product as chloral hydrate. Molecular Pharmacology, 1, 247.254.

Cowles, A. L., Borgstedt, H. H., and Gillies, A. J. (1971). Tissue weights and rates of blood flow in man for the prediction of anesthetic uptake and distribution. Anesthesiology, 35 (5), 523-526.

Documenta Geigy (1963). Tables Scientifiques, 6th edition, pp. 642-643. Geigy: Basel.

Eger, E. I. II (1963). A mathematical model of uptake and distribution. In Uptake and Distribution of Anesthetic Agents, pp. 72-87. Edited by E. M. Papper and R. J. Kitz. McGraw-Hill: New York.

Ertle, T., Henschler, D., Müller, G., and Spassovski, M. (1972). Metabolism of trichlorethylene in man. The significance of trichlorethanol in long-term exposure conditions. Archives of Toxicology, 29, 171-188.

Fernández, J. G., Humbert, B. E., Droz, P. O., and Caperos, J. R. (1975). Exposition au trichloréthylène. Bilan de l'absorption, de l'excrétion et du métabolisme sur des sujets humains. Archives des Maladies Professionnelles, 36, (7-8) $397-407$.

Fernández, J. G., Humbert, B. E., Droz, P. O., and Caperos, 
J. R. (1977a). Pulmonary absorption and elimination of trichlorethylene. Significance of alveolar air as an index of exposure. (In preparation).

Fernández, J. G., Humbert, B. E., Droz, P. O., and Caperos, J. R. (1977b). Experimental human exposures to trichlorethylene. Metabolism and urinary excretion of trichloracetic acid and trichlorethanol as indicators of occupational exposure. (In preparation).

Fiserova-Bergerova, V., Vlach, J., and Singhal, K. (1974). Simulation and prediction of uptake, distribution, and exhalation of organic solvents. British Journal of Industrial Medicine, 31, 45-52.

Guberan, E., and Fernández, J. (1974). Control of industrial exposure to tetrachloroethylene by measuring alveolar concentrations: theoretical approach using a mathematical model. British Journal of Industrial Medicine, 31, 159-167.

Hagler, K. (1969). In Gas Chromatography in Biology and Medicine, p. 86. Edited by R. Porter. Churchill: London.

Ikeda, M., and Imamura, T. (1973). Biological half-life of trichlorethylene and tetrachloroethylene in human subjects. International Archives of Occupational and Environmental Health, 31, 209-224.

Kety, S. S. (1951). The theory and applications of the exchange of inert gas at the lungs and tissues. Pharmacological Reviews, 3, 1-41.

Kimmerle, G., and Eben, A. (1973). Metabolic studies of trichlorethylene. II. Experimental human exposure. Archives of Toxicology, 30, 127-138.

Leibman, K. C. (1965). Metabolism of trichlorethylene in liver microsomes. I. Characteristics of the reaction. Molecular Pharmacology, 1, 239-246.

Mapleson, W. W. (1963). An electric analogue for uptake and exchange of inert gases and other agents. Journal of Applied Physiology, 18, 197-204.

Marshall, E. K., and Owens, A. H. (1954). Absorption, excretion and metabolic fate of chloral hydrate and trichlorethanol. Dulletin of the Johns Hopkins Hospital, 94, 1-18.

Müller, G., Spassovski, M., and Henschler, D. (1972). Trichloroethylene exposure and trichloroethylene metabolites in urine and blood. Archives of Toxicology, 29, 335340.

Müller, G., Spassovski, M., and Henschler, D. (1974). Metabolism of trichloroethylene in man. II. Pharmacokinetics of metabolites. Archives of Toxicology, 32, 283-295.

Müller, G., Spassovski, M., and Henschler, D. (1975). Metabolism of trichloroethylene in man. III. Interaction of trichloroethylene and ethanol. Archives of Toxicology, 33, 173-189.

Nomiyama, K., and Nomiyama, H. (1971). Metabolism of trichloroethylene in humans. Sex difference in urinary excretion of trichloroacetic acid and trichloroethanol. International Archives of Occupational and Environmental Health, 28, 37-48.

Ogata, M., Takatsuka, Y., and Tomokuni, K. (1971). Excretion of organic chlorine compounds in the urine of persons exposed to vapours of trichloroethylene and tetrachloroethylene. British Journal of Industrial Medicine, 28, 386-391.

Owens, A. H., and Marshall, E. K. (1955). Further studies on the metabolic fate of chloral hydrate and trichloroethanol. Bulletin of the Johns Hopkins Hospital, 97, 395-404.

Paykoç, Z. V., and Powell, J. F. (1945). The excretion of sodium trichloracetate. Journal of Pharmacology and Experimental Therapeutics, 85, 289-293.

Sellers, E. M., and Koch-Weser, J. (1971). Kinetics and clinical importance of displacement of wafarin from albumin by acidic drugs. Annals of the New York Academy of Sciences, 179, 213-225.

Souček, B., and Vlachová, D. (1960). Excretion of trichloroethylene metabolites in human urine. British Journal of Industrial Medicine, 17, 60-64.

Steward, A., Allott, P. R., Cowles, A. L., and Mapleson, W. W. (1973). Solubility coefficients for inhaled anaesthetics for water, oil and biological media. British Journal of Anaesthesiology, 45, 282-293.

Stewart, R. D., Hake, C. L., and Peterson, J. E. (1974). Use of breath analysis to monitor trichlorethylene exposures. Archives of Environmental Health, 29, 6-13.

\section{Appendix}

\section{UPTAKE, DISTRIBUTION, AND ELIMINATION OF TRICHLOROETHYLENE}

\section{Pulmonary compartment}

The difference between the solvent quantity which enters the compartment and that which leaves it during the interval of time $\mathrm{dt}$ corresponds to the variation in concentration of the solvent in the compartment multiplied by the apparent volume of distribution:

$$
\begin{array}{r}
\dot{V}_{A} P_{I} d t-\dot{V}_{A} P_{A} d t-P_{A} \dot{Q}_{L U} \lambda_{b} d t+P_{V} \dot{Q}_{L U} \lambda_{b} d t= \\
\left(V_{A}+T_{p} \lambda_{p}+Q_{b} \lambda_{b}\right) d P_{A}
\end{array}
$$

The partial pressure in the mixed venous blood $P_{v}$ represents the mean of the partial pressures in the different tissues and in the blood weighted by the respective perfusions $\left(\mathrm{cf}\right.$. $i^{\text {th }}$ tissue and metabolic compartments):

$$
\mathbf{P}_{\mathbf{V}}=\sum^{\mathrm{i}} \mathbf{P}_{\mathbf{i}} \dot{Q}_{\mathrm{i}} / \mathbf{Q}+\mathbf{P}_{\mathrm{A}} \dot{Q}_{\mathrm{L}} \mathbf{Q}_{\mathrm{L}} / \mathbf{Q}\left(\mathbf{Q}_{\mathrm{L}}+\mathbf{T}_{\mathrm{L}} \lambda_{\mathrm{L}} / \lambda_{\mathrm{b}}\right)
$$

Finally, the relation between $P_{A}$ and the different $\mathbf{P}_{\mathbf{i}}$ is expressed:

$$
\mathrm{dP}_{\mathrm{A}} / \mathrm{dt}=\mathrm{AV} \dot{V}_{\mathrm{A}} \mathbf{P}_{\mathrm{I}} \mathrm{dt}+\mathrm{A} \dot{Q}_{\mathrm{LU}} \lambda_{\mathrm{b}} \sum^{\mathrm{i}} \mathbf{P}_{\mathrm{i}} \dot{Q}_{\mathrm{i}} / \mathbf{Q}+
$$

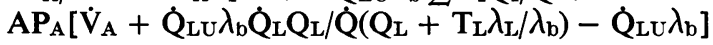
with

$$
\mathrm{A}=1 /\left(\mathrm{V}_{\mathrm{A}}+\mathrm{T}_{\mathrm{p}} \lambda_{\mathrm{p}}+\mathrm{Q}_{\mathrm{b}} \lambda_{\mathrm{b}}\right)
$$

$-i^{\text {th }}$ tissue compartment.

A similar discussion to that applied in the pulmonary compartment leads to the following equation:

therefore

$$
\dot{Q}_{i} \lambda_{b} P_{A} d t-\dot{Q}_{i} \lambda_{b} P_{i} d t=\left(T_{i} \lambda_{i}+Q_{i} \lambda_{b}\right) d P_{i}
$$

$$
\mathrm{dP} \mathbf{P}_{\mathrm{i}} / \mathrm{dt}=\dot{\mathrm{Q}}_{\mathrm{i}} \lambda_{\mathrm{b}}\left(\mathbf{P}_{\mathrm{A}}-\mathbf{P}_{\mathrm{i}}\right) /\left(\mathrm{T}_{\mathrm{i}} \lambda_{\mathrm{i}}+\mathbf{Q}_{\mathrm{i}} \lambda_{\mathrm{b}}\right)
$$

We thus obtain four interdependent differential equations, which give the partial pressures in the different compartments.

\section{Metabolic compartment}

The blood reaches the liver with a partial pressure $\mathbf{P}_{\mathrm{A}}$. As it is desired to determine the partial pressure $P_{v L}$ (venous blood) outside this organ, it is assumed that 
metabolism takes place after equilibrium, according to the partition coefficient:

$$
\mathbf{P}_{\mathrm{VL}} / \mathbf{P}_{\mathrm{A}}=\mathrm{Q}_{\mathrm{L}} /\left(\mathrm{Q}_{\mathrm{L}}+\mathrm{T}_{\mathrm{L}} \lambda_{\mathrm{L}} / \lambda_{\mathrm{b}}\right)
$$

\section{FORMATION AND URINARY ELIMINATION}

OF TCE AND TCA

The formation rates of TCE and TCA from $\mathrm{CH}$ are determined by the total quantity of TRI metabolised per unity of time given by the equations of the distribution of TRI. The rate of formation of $\mathrm{CH}$ is described by the equation:

$$
\mathrm{R}_{\mathrm{CH}}=\mathrm{K} \dot{\mathrm{Q}}_{\mathrm{L}} \lambda_{\mathrm{b}} \mathbf{P}_{\mathrm{A}}\left[1-\mathrm{Q}_{\mathrm{L}} /\left(\mathrm{Q}_{\mathrm{L}}+\mathrm{T}_{\mathrm{L}} \lambda_{\mathrm{L}} / \lambda_{\mathrm{b}}\right)\right]
$$

with $\mathrm{K}=$ constant of transformation ppm $-\mathrm{mg} / \mathrm{l}$ (0.00489)

The formation rates of TCE and TCA, RTCE, and $R_{T C A}$ respectively, are expressed by the equations:

$$
\begin{aligned}
& \mathbf{R}_{\mathrm{TCE}}=\mathbf{R}_{\mathrm{CH}} \mathrm{k}_{\mathrm{CE}} /\left(\mathrm{k}_{\mathrm{CE}}+\mathrm{k}_{\mathrm{CA}}\right) \\
& \mathbf{R}_{\mathrm{TCA}}=\mathbf{R}_{\mathrm{CH}} \mathrm{k}_{\mathrm{CA}} /\left(\mathrm{k}_{\mathrm{CE}}+\mathrm{k}_{\mathrm{CA}}\right)
\end{aligned}
$$

All the metabolic processes are therefore directly proportional to the partial pressure of TRI in the blood.

The TCE thus formed is distributed in one single compartment of volume $V_{\text {TCE. }}$. The variations in the concentration of TCE can, therefore, be expressed by the following equation:

$\mathrm{dC}_{\mathrm{TCE}} / \mathrm{dt}=\mathrm{R}_{\mathrm{TCE}} / \mathrm{V}_{\mathrm{TCE}}-\mathrm{k}_{\mathrm{EU}} \mathrm{C}_{\mathrm{TCE}}-\mathrm{k}_{\mathrm{EA}} \mathrm{C}_{\mathrm{TCE}}-\mathrm{k}_{\mathrm{E}} \mathrm{C}_{\mathrm{TCE}}$

By multiplying by $\mathrm{V}_{\mathrm{TCE}}$, this equation becomes:

$\mathrm{dW}_{\mathrm{TCE}} / \mathrm{dt}=\mathbf{R}_{\mathrm{TCE}}-\left(\mathrm{k}_{\mathrm{EU}}+\mathrm{k}_{\mathrm{EA}}+\mathrm{k}_{\mathrm{E}}\right) \mathrm{W}_{\mathrm{TCE}}$ where $\mathbf{W}_{\text {TCE }}=\mathrm{V}_{\mathrm{TCE}} \mathrm{C}_{\mathrm{TCE}}$ is the quantity of TCE in the compartment of distribution. Each of the terms $\mathrm{k}_{\mathrm{EU}} \mathrm{W}_{\mathrm{TCE}}, \mathrm{k}_{\mathrm{EA}} \mathrm{W}_{\mathrm{TCE}}$, and $\mathrm{k}_{\mathrm{E}} \mathrm{W}_{\mathrm{TCE}}$ represents respectively the elimination rates by the urine, in the form of TCA, and other elimination routes or metabolic pathways. The elimination by the urine can therefore be expressed in the following way: $\mathrm{dR} \mathbf{R U}_{\mathrm{EU}} / \mathrm{dt}=\mathrm{k}_{\mathrm{EU}}\left[\mathrm{R}_{\mathrm{TCE}}-\left(\mathrm{k}_{\mathrm{EU}}+\mathrm{k}_{\mathrm{EA}}+\mathrm{k}_{\mathrm{E}}\right) \mathbf{R}_{\mathrm{EU}} / \mathrm{k}_{\mathrm{EU}}\right]$
Similarly, the variations in the concentration of TCA in the volume of distribution $\mathrm{V}_{\mathrm{TCA}}$ can be expressed by the following equation:

$$
\mathrm{dC}_{\mathrm{TCA}} / \mathrm{dt}=\mathbf{R}_{\mathrm{TCA}} / \mathrm{V}_{\mathrm{TCA}}+\mathrm{R}_{\mathrm{EA}} / \mathrm{V}_{\mathrm{TCA}}-\mathrm{k}_{\mathrm{AU}} \mathrm{C}_{\mathrm{TCA}}-\mathrm{k}_{\mathrm{A}} \mathrm{C}_{\mathbf{T C A}}
$$

where $R_{E A}=$ formation rate of TCA from TCE. But:

$$
\mathbf{R}_{\mathbf{E A}}=\mathbf{R}_{\mathrm{EU}} \mathbf{k}_{\mathrm{EA}} / \mathbf{k}_{\mathrm{EU}}
$$

We thus obtained by multiplying by $\mathrm{V}_{\text {TCA }}$ :

$\mathrm{dW}_{\mathrm{TCA}} / \mathrm{dt}=\mathbf{R}_{\mathrm{TCA}}+\mathrm{R}_{\mathrm{EUk}} \mathrm{kA}_{\mathrm{EA}} /$

$$
k_{\text {EU }}-k_{A} W_{\text {TCA }}-k_{\text {AU }} W_{\text {TCA }}
$$

where $\mathrm{W}_{\mathrm{TCA}}=\mathrm{V}_{\mathrm{TCA}} \mathrm{C}_{\mathrm{TCA}}$ is the quantity of TCA in the compartment as in the case of TCE we can express the urinary elimination rate of TCA, $R_{A U}$ :

$$
\begin{gathered}
d R_{A U} / d t=k_{A U}\left[R_{T C A}+R_{E U} k_{E A} / k_{E U}\right. \\
\left.-\left(k_{A}+k_{A U}\right) R_{A U} / k_{A U}\right]
\end{gathered}
$$

\begin{tabular}{|c|c|}
\hline 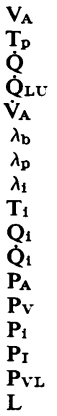 & $\begin{array}{l}\text { volume of alveolar gas } \\
\text { volume of lung tissue } \\
\text { cardiac output } \\
\text { blood flow through the lungs } \\
\text { alveolar ventilation } \\
\text { blood-gas partition coefficient } \\
\text { lung tissue-gas partition coefficient } \\
\mathrm{i}^{\text {th }} \text { tissue-gas partition coefficient } \\
\text { volume of the } \mathrm{i}^{\text {th }} \text { tissue } \\
\text { blood volume in equilibrium with the } \mathrm{i}^{\text {th }} \text { tissue } \\
\text { blood flow through the } \mathrm{i}^{\text {th }} \text { tissue } \\
\text { partial pressure in arterial blood } \\
\text { partial pressure in venous blood } \\
\text { partial pressure in the } \mathrm{i}^{\text {th }} \text { tissue } \\
\text { partial pressure in inspired air } \\
\text { partial pressure in liver venous blood } \\
\text { as a suffix refers to liver }\end{array}$ \\
\hline
\end{tabular}

The mathematical analysis of the absorption, elimination, and metabolism of TRI leads to six interdependent differential equations. Using the Runge-Kutta-Gill method of integration, a program was written in FORTRAN IV to solve this system of equations on a IBM 1130 computer.

Table 4 Symbols used in the mathematical equations 